\title{
Conservative management of postmenopausal woman with prolonged use of the dislocated intrauterine device which was also unnoticed while hysterectomy
}

\section{Mustafa Gazi Uçar*, Tansel Çakır, Tolgay Tuyan İlhan, Çetin Çelik}

Department of Obstetrics \& Gynecology, Faculty of Medicine, Selçuk University, Konya, Turkey

Received: 02 July 2015

Accepted: 14 August 2015

\section{*Correspondence:}

Dr. Mustafa Gazi Uçar,

E-mail: mustafa_gazi_ucar@hotmail.com

Copyright: (C) the author(s), publisher and licensee Medip Academy. This is an open-access article distributed under the terms of the Creative Commons Attribution Non-Commercial License, which permits unrestricted non-commercial use, distribution, and reproduction in any medium, provided the original work is properly cited.

\begin{abstract}
The objectives of this study are to identify and compare the treatment options of woman with uterine perforation caused by intrauterine device (IUD). A 74-years-old woman presented with irritable voiding symptoms and a dislocated IUD into the peritoneal cavity was discovered incidentally during radiologic imaging. While a Lippes loop IUD had been inserted 35 years previously, she had a history of hysterectomy 10 years after an IUD insertion. Not only the patient had forgotten the presence of the IUD, but also it was unnoticed during hysterectomy. Patient has remained asymptomatic for over the 25 years, with the prolonged use of dislocated IUD. The patient managed conservatively and no need for surgical intervention. Once a gynaecologist is faced with the dilemma of whether it is necessary to remove a dislocated IUD or not, patients should undergo an individualized management, balancing both risks and benefits of surgical intervention. Asymptomatic elderly patients with comorbidities may benefit from conservative management with close monitoring.
\end{abstract}

Keywords: Mislocated IUD, Uterus perforation, Lippes loop, Conservative management, Hysterectomy

\section{INTRODUCTION}

Intrauterine Contraceptive Devices (IUDs) are safe, widely used, highly effective, economic, and a reversible long-acting form of contraception. The usage of IUD can be accompanied by various complications; including migration, expulsion, embedment, and perforation. Perforation of the uterus by an IUD is rare with a reported incidence of 0.2-3.6 per 1000 insertions. ${ }^{1-3}$ This not only, increases the risk of contraceptive failure, but also puts the patient at probable further complications. Migration into the peritoneal cavity can causes serious complications such as adhesion-fistula formation, infection, abscess and perforation into bowel, bladder or blood vessels. ${ }^{2,4}$ In addition to direct impact, adhesion formation can cause chronic pain, intestinal obstruction and infertility.
Several risk factors for uterine perforation have been described in literature. Breastfeeding and proximity to a recent delivery (up to 36 weeks) were both independently associated with an increased risk of uterine perforation.1 In addition to timing of the insertion, history of caesarean delivery, the skill and experience of performing physician and position of uterus or presence of a uterine anomaly are reported risk factors of uterine perforation. ${ }^{1-3,5,6}$ It is not well known whether this complication occur secondary to a technical error or was related to the patient's own conditions.

Herein, we report a case of postmenopausal asymptomatic woman with prolonged use of the dislocated Lippes loop IUD, which was also unnoticed while hysterectomy. 


\section{CASE REPORT}

A 74-years-old postmenopausal woman, gravida 6, para 6 was admitted to our outpatient clinic with lower abdominal and flank pain, and voiding symptoms of frequency, urgency and dysuria. She has a past medical history of noninsulin-dependent diabetes mellitus and hypertension. Given her history of the irritable voiding symptoms, and abdominal pain having persisted for 1 day, plain abdominal radiography and urine testing were ordered. Urinalysis revealed urinary tract infection and empirical antibiotic therapy was started. Quick relief from irritative symptoms was achieved when she had received antibiotic therapies. Plain X-ray of the abdomen revealed a dislocated Lippes loop IUD which was located on the right side of the pelvic wall (Figure 1).

After extensive questioning of the patient's medical history, we have learned that a Lippes loop IUD had been inserted 35 years previously. While she was still breastfeeding, eight weeks after her last vaginal delivery, the patient was fitted with a Lippes loop-type IUD. The patient had forgotten the presence of the IUD. In an interesting manner, 10 years after an IUD insertion, she had a history of hysterectomy about 25 years previously due to heavy-extended uterine bleeding refractory to medical treatment. It is, however, difficult to exactly predict when migration has occurred, patient also has remained asymptomatic for over the 25 years, with the prolonged use of dislocated IUD.

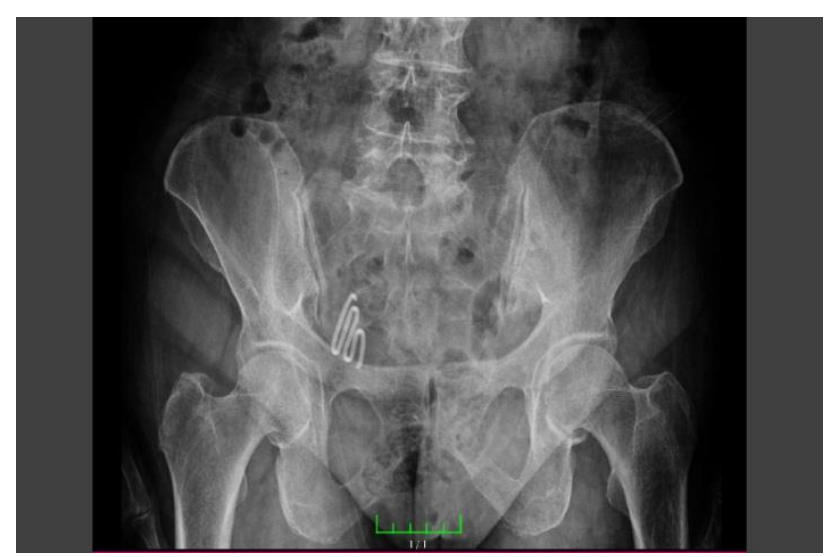

Figure 1: The X-ray image of dislocated IUD.

IUD: intrauterine device

Since magnetic resonance imaging (MRI) is safe to perform at lippes loop and offers high contrast resolution, provides good tissue characterization, patients scheduled for MRI. MRI scan revealed the dislocated IUD which was in the right side of pelvic area near the rectum without any organ or vessel injury (Figure 2).

The patient managed conservatively without any surgical intervention.

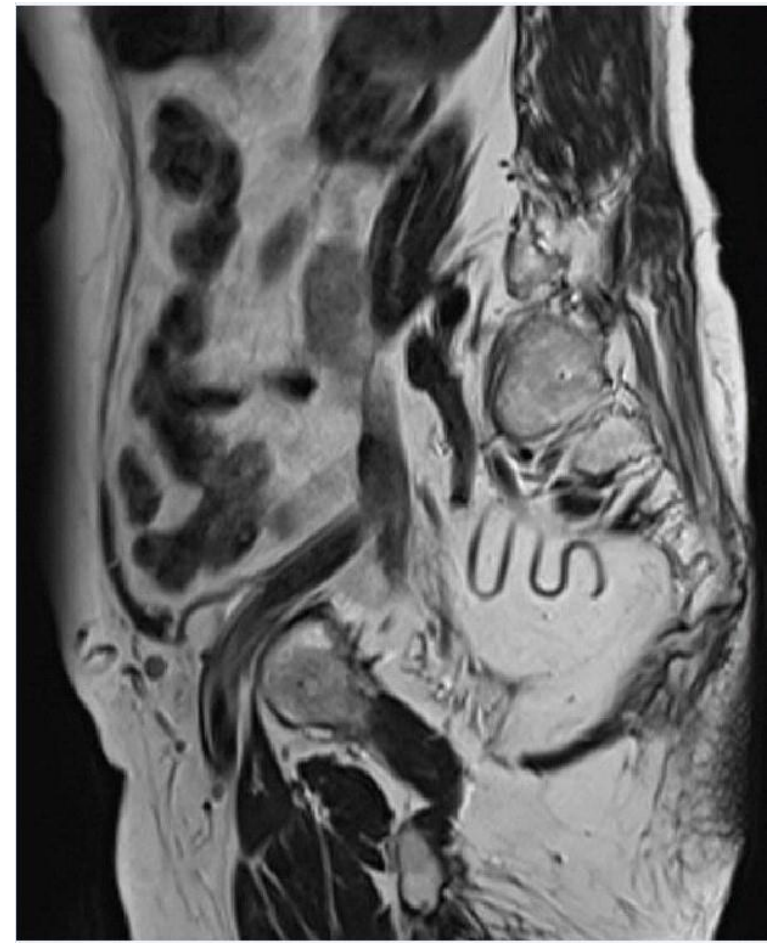

Figure 2: Sagittal plane MRI images of dislocated IUD.

MRI: magnetic resonance imaging, IUD: intrauterine device

\section{DISCUSSION}

Uterine perforation associated with IUDs, raises several questions: When should this complication be suspected? And should removal of a dislocated IUDs, routinely performed even if patients are asymptomatic?

Uterine perforation following IUD insertion is not diagnosed promptly as it is asymptomatic in most cases. ${ }^{5}$ This complication is always initiated at the time of IUD insertion. ${ }^{5,6}$ However migration can occur spontaneously and later dislocation of IUD into the abdominal cavity is possible which makes them undetectable at the time of insertion. The majority of women with IUD perforation experience mild symptoms of abnormal bleeding and/or mild lower abdominal pain. ${ }^{7}$ In this study IUD was discovered incidentally during radiologic imaging studies performed because of unrelated symptoms.

The need to remove intra-abdominal IUDs in asymptomatic cases has repeatedly been questioned and the management is somewhat controversial. The mainstay of the indications for surgical intervention of a migrated IUD to the abdominal cavity is the serious complications or potential serious complications that might occur if the IUD should remain in the abdomen. Once an IUD is noted to be missing, Kho and Chamsy recommend prompt removal because that may limit the need for a more extensive procedure and prevent complications such as abdominal abscess and fistula formation. ${ }^{2}$ Conversely, Inal et al. suggested that a dislocated IUD in an 
asymptomatic patient does not need to be surgically removed. ${ }^{6}$ In addition to other possible intra- and postoperative complications, removal may create more complications than just leaving it in elderly patients with comorbidities. By the fact, a surgical approach will not prevent adhesion formation which itself can lead to adhesion; Markovitch et al., suggested that it is not reasonable to intervene surgically in asymptomatic patients after perforation. ${ }^{8}$

When symptomatic, traditional form of treatment has been laparotomy, but with developing surgical techniques, laparoscopy, being less invasive and more safe, is nowadays the treatment of choice. Minilaparotomy is cost-saving procedure which can be alternative to laparoscopy with less need for equipment. ${ }^{9}$

To the best of our knowledge, this was the first case of dislocated intrauterine device which was also unnoticed while hysterectomy. To avoid unnecessary referrals and treatment delay, all patients should be questioned about contraceptive methods as a part of clinical preoperative assessment. At the same time we suggest carefully inspecting the nearby uterus, pelvis and any adhesions during hysterectomy that should guide as a warning to surgeons and patients alike. Clinicians should be aware of this complication in every patient with a history of IUD use and the location of the device needs to be confirmed.

\section{CONCLUSIONS}

Once a gynaecologist is faced with the dilemma of whether it is necessary to remove a dislocated IUD or not, patients should undergo an individualized management, balancing both risks and benefits of surgical intervention. Asymptomatic elderly patients with comorbidities may benefit from conservative management with close monitoring.

Funding: No funding sources Conflict of interest: None declared

Ethical approval: Not required

\section{REFERENCES}

1. Heinemann K, Reed S, Moehner S, Minh TD. Risk of uterine perforation with levonorgestrel-releasing and copper intrauterine devices in the European Active Surveillance Study on Intrauterine Devices. Contraception. 2015;91:274-9.

2. Kho KA, Chamsy DJ. Perforated intraperitoneal intrauterine contraceptive devices: diagnosis, management, and clinical outcomes. J Minim Invasive Gynecol. 2014;21:596-601.

3. Kaislasuo J, Suhonen S, Gissler M, Lähteenmäki P, Heikinheimo O. Intrauterine contraception: incidence and factors associated with uterine perforation - a population-based study. Hum Reprod. 2012;27:265863.

4. Vasquez P, Schreiber CA. The missing IUD. Contraception. 2010; 82:126-8.

5. Caliskan E, Oztürk N, Dilbaz BO, Dilbaz S. Analysis of risk factors associated with uterine perforation by intrauterine devices. Eur J Contracept Reprod Health Care. 2003;8:150-5.

6. Inal HA, Ozturk Inal Z, Alkan E. Successful conservative management of a dislocated IUD. Case Rep Obstet Gynecol. 2015;2015:130528.

7. Kaislasuo J, Suhonen S, Gissler M, Lähteenmäki P, Heikinheimo O. Uterine perforation caused by intrauterine devices: clinical course and treatment. Hum Reprod. 2013;28:1546-51.

8. Markovitch O, Klein Z, Gidoni Y, Holzinger M, Beyth Y. Extrauterine mislocated IUD: is surgical removalmandatory? Contraception. 2002;66:105-8.

9. Ertopcu K, Nayki C, Ulug P, Nayki U, Gultekin E, Donmez A, et al. Surgical removal of intraabdominal intrauterine devices at one center in a 20year period. Int J Gynaecol Obstet. 2015;128:10-3.

Cite this article as: Uçar MG, Çakır T, İlhan TT, Çelik Ç. Conservative management of postmenopausal woman with prolonged use of the dislocated intrauterine device which was also unnoticed while hysterectomy. Int J Reprod Contracept Obstet Gynecol 2015;4:1565-7. 